Thorax (1964), 19, 397.

\title{
Maintenance of chest wall stability
}

\author{
B. T. LE ROUX \\ From the Department of Thoracic Surgery, The Royal Infirmary, Edinburgh
}

The surgeon is faced with the need to assist in the maintenance of stability of the chest wall in two sets of circumstances: (1) when stability has been disrupted by ascidental trauma with resultant 'flail' or 'stove-in' chest ; (2) when stability has been jeopardized by surgical intervantion, likely again in two circumstances: (a) with intentional mobilization of part of the chest wall, usually the sternum, for correction of congenital deformities, of which pectus excavatum is the most common, and $(b)$ with resection of part of the chest wall in the management of primary or metastatic rib tumours, or pulmonary tumours which have invaded the chest wall.

The purpose of this paper is to list some of the methods described in the literature for the maintenance of chest wall stability (and from their number none can be uniformly satisfactory) and to review the methods used, in the circumstances outlined above, in the Regional Thoracic Unit in Edinburgh.

\section{FLAIL CHEST}

The reasons for and the urgency of stabilizing a flail chest are now well recognized (Barrett, 1960). Fixation of the mobile segment in an orthopaedic sense is difficult and probably unnecessary, and the object of treatment is the prevention of paradoxical movement of the chest wall with respiration. The time-honoured method, of Hippocratic antiquity, is by external support, with strapping applied directly or over pads, or with sandbags or bags containing lead shot. External support is sometimes a satisfactory manœuvre both as a 'first-aid' gesture and, with devoted maintenance of a clear airway, as definitive management (Sandor, 1963). All methods of external support have, however, this in common-they hide from the observer visual evidence of paradoxical movement of the mobile segment whether or not they prevent it, and the surgical trainee, still often responsible for the early management of patients with flail chest, may, by not seeing paradoxical movement, be persuaded that stability of the chest wall has been achieved. The patient's respiratory efforts may well be less strenuous, because movement of the chest wall has been inhibited by the strapping; and when to this deceptive calm is added the effect of morphia used to diminish pain, the stage is set for the disasters which are consequent upon hypoxia and the retention of carbon dioxide. There is certainly a group of patients in whom the extent of trauma to the thoracic cage justifies their inclusion in the group of stove-in chest injuries and in whom the application of strapping, with or without tracheostomy (Carter and Giuseffi, 1951), has been successful ; but where disruption of the respiratory mechanics is more than trivial other steps are usually necessary to maintain satisfactorily stability of the chest wall.

The alternative forms of management fall into three groups: (1) Fixation, which may be called 'closed', since fracture sites are not exposed, and which depends on the use of various types of hooks and slings, towel clips or transfixing pins, more commonly suggested as satisfactory where the mobile segment includes the sternum, which is slung by these supports to a plaster or other form of cuirass or to a specially designed frame (Heroy and Eggleston, 1951; Hudson, McElvenny, and Head, 1954 ; Proctor and London, 1955; and Sillar, 1962); (2) fixation of the fractured ribs at open operation by wiring, stapling, or intramedullary nailing (Blades and Kent, 1940 ; Coleman and Coleman, 1950 ; Crutcher and Nolen, 1956); and (3) indirect splinting of the chest wall by intermittent positive pressure artificial respiration through a cuffed tracheostomy tube in a patient pharmacologically rendered apnoeic (Avery, Mörch, and Benson, 1956 ; Griffiths, 1960).

The methods of closed fixation are criticized on the grounds that they fail adequately to control paradox and easily cut out, and this criticism is substantiated by the experience in Edinburgh with some of these methods in the early part of the last decade. Internal fixation of fractured rib ends by wiring has been reported to fail to achieve its object (Windsor and Dwyer, 1961) and has also been seen to fail in Edinburgh (Griffiths, 1960). It is the patient whose mobile chest most needs fixation who is usually least able to tolerate an 
extensive procedure, the aim of which is internal fixation of a large number of fractures, many of them through cartilage, and many of those through rib difficult to identify on chest radiographs obscured by surgical emphysema and mottled, traumatized lung.

In Edinburgh, flail chest is now routinely managed by tracheostomy and intermittent positive pressure respiration. Paradoxical movement of the chest wall is corrected, and, although some patients with extensive rib fractures are left with considerable deformity (Fig. 1), no attempt has yet been made successfully to combine internal fixation to prevent deformity with intermittent positive pressure respiration to control paradox.

\section{PECTUS EXCAVATUM}

The correction of funnel chest deformity is generally acknowledged to be a worthwhile procedure for both functional and cosmetic reasons. It is well recognized that the grosser degrees of pectus excavatum, particularly in adolescence, are usually associated with more extensive deformity of the chest, and the generally miserable 'drooping-lily' appearance of the tall, asthenic kyphotic youth with sloping shoulders is well known. While correction of the funnel chest does little to improve the posture and appearance of these patients, an increase in respiratory reserve can usually be demonstrated with respiratory function tests, and in general a deformity is psychological more acceptable when it is associated with a sca옹.

Operations designed for the repair of funnel chest deformity nearly always include mobilizas tion of the sternum with detachment from it the diaphragm, excision or multiple wedge chon drotomies of the deformed costal cartilages, and transverse cuneiform osteotomy of the sternumb in the vicinity of the manubrio-gladiolar junctio (Ravitch, 1958). More limited procedures i infants (Brown, 1939 ; Chin and Adler, 1954) arg reported to be followed by a recurrence rate which makes them unacceptable. While thes general plan for correction of the deformity is accepted, there is no agreement on the need for support of the mobilized sternum. Some (Daniet, 1958 ; Ravitch, 1961) maintain that there is $\mathrm{n}$ need to support the mobilized sternum other tha with sutures, preferably of silk, through bone of periosteum to close the sternal osteotomy. Othe (Dorner, Keil, and Schissel, 1950 ; Lester, 1950 Holmes, 1957 ; Paltia, Parkkalainen, Salamaa, an\& Wallgren, 1959; Mayo and Long, 1962) have found the sternum too mobile, and a variety o methods have been described to prevent paras doxical movement during convalescence. Th problem is similar to that of the mobile sternures after 'steering-wheel' injuries; the differences ar that there is no need to decide whether or not an open operation should be undertaken since ong has already been made, the precise situation of

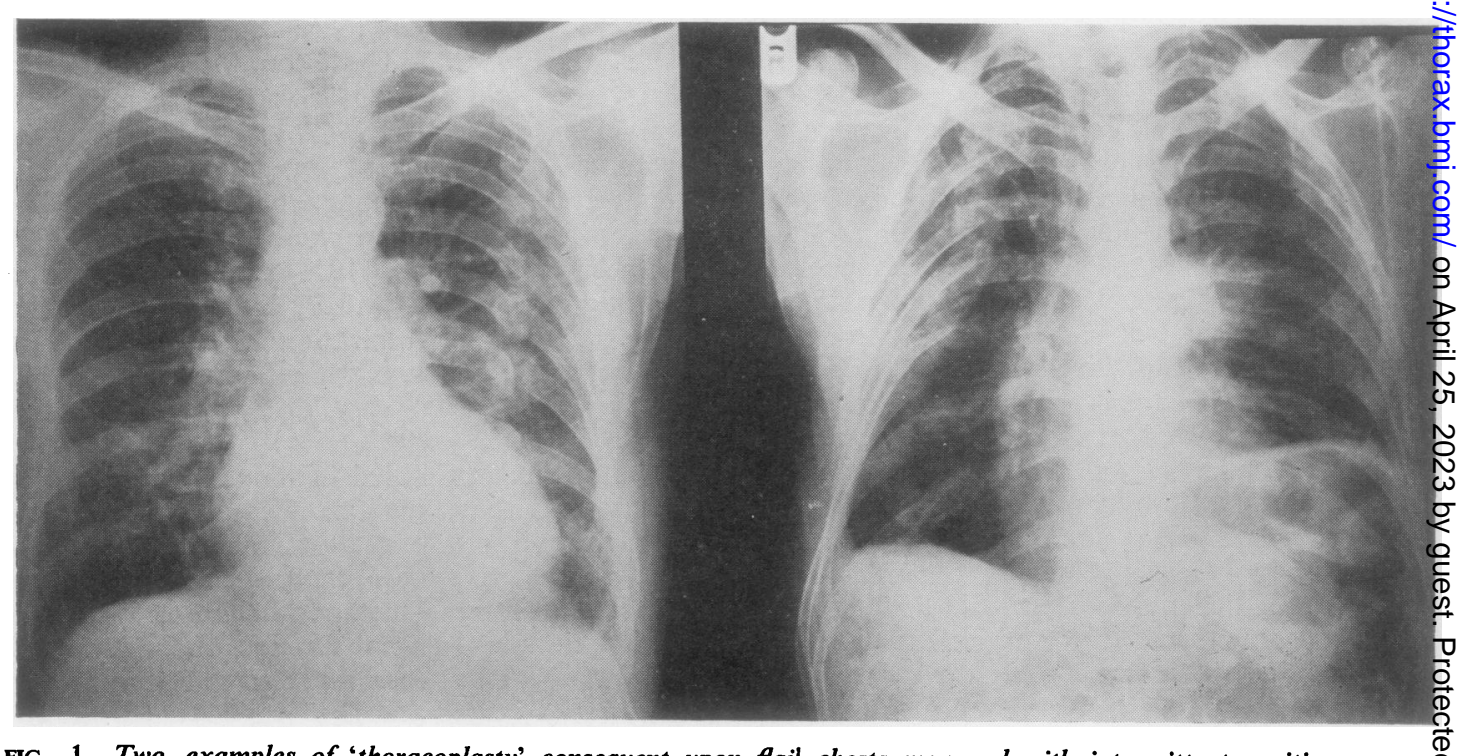

FIG. 1. Two examples of 'thoracoplasty' consequent upon flail chests managed with intermittent positive pressure respiration. The patients to whom the films refer are both well and have returned to their previous occupatiog (they were both miners iniured in falls of rock) and neither is aware of diminution in exercise tolerance. 


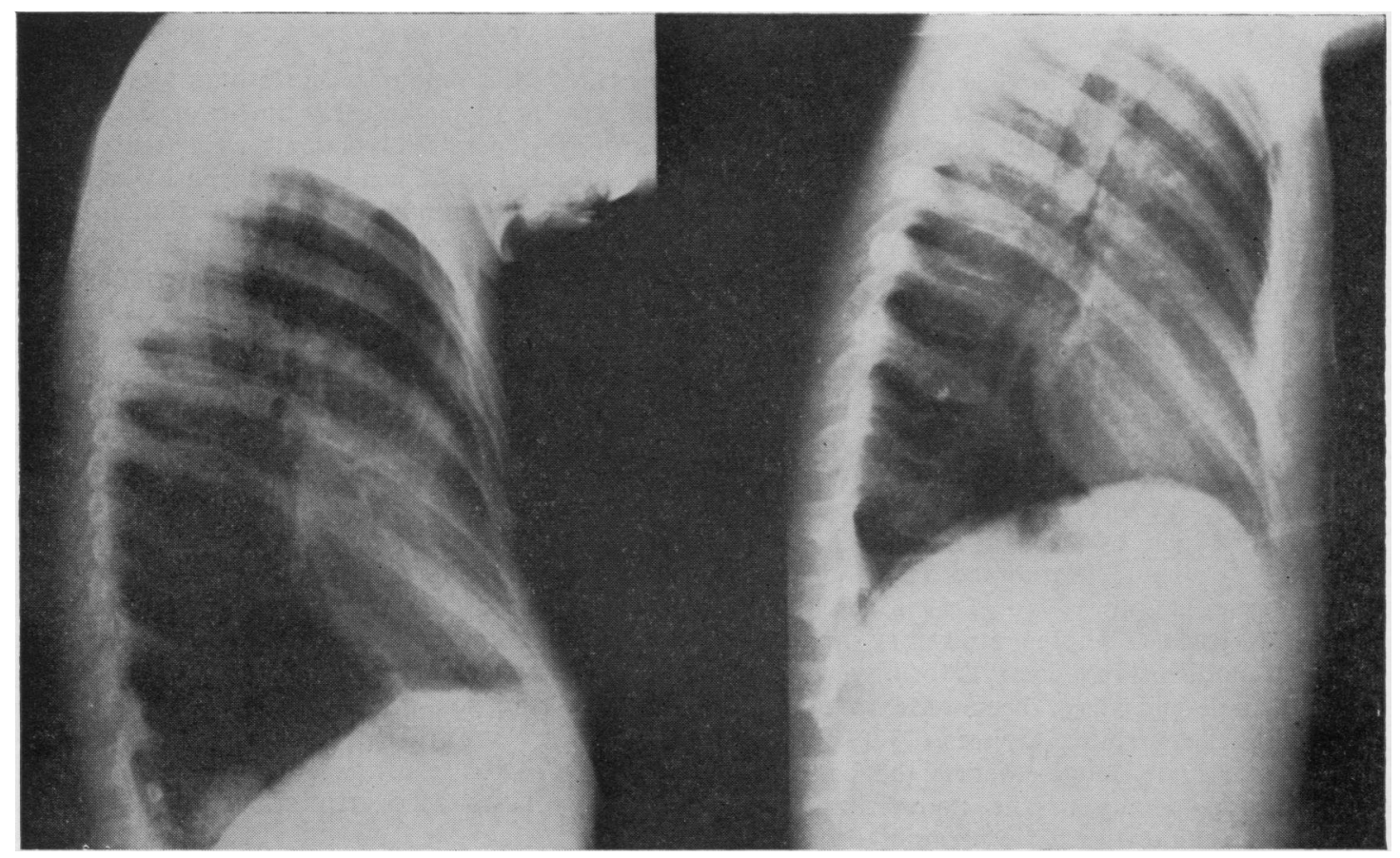

FIG. $2 \mathrm{a}$

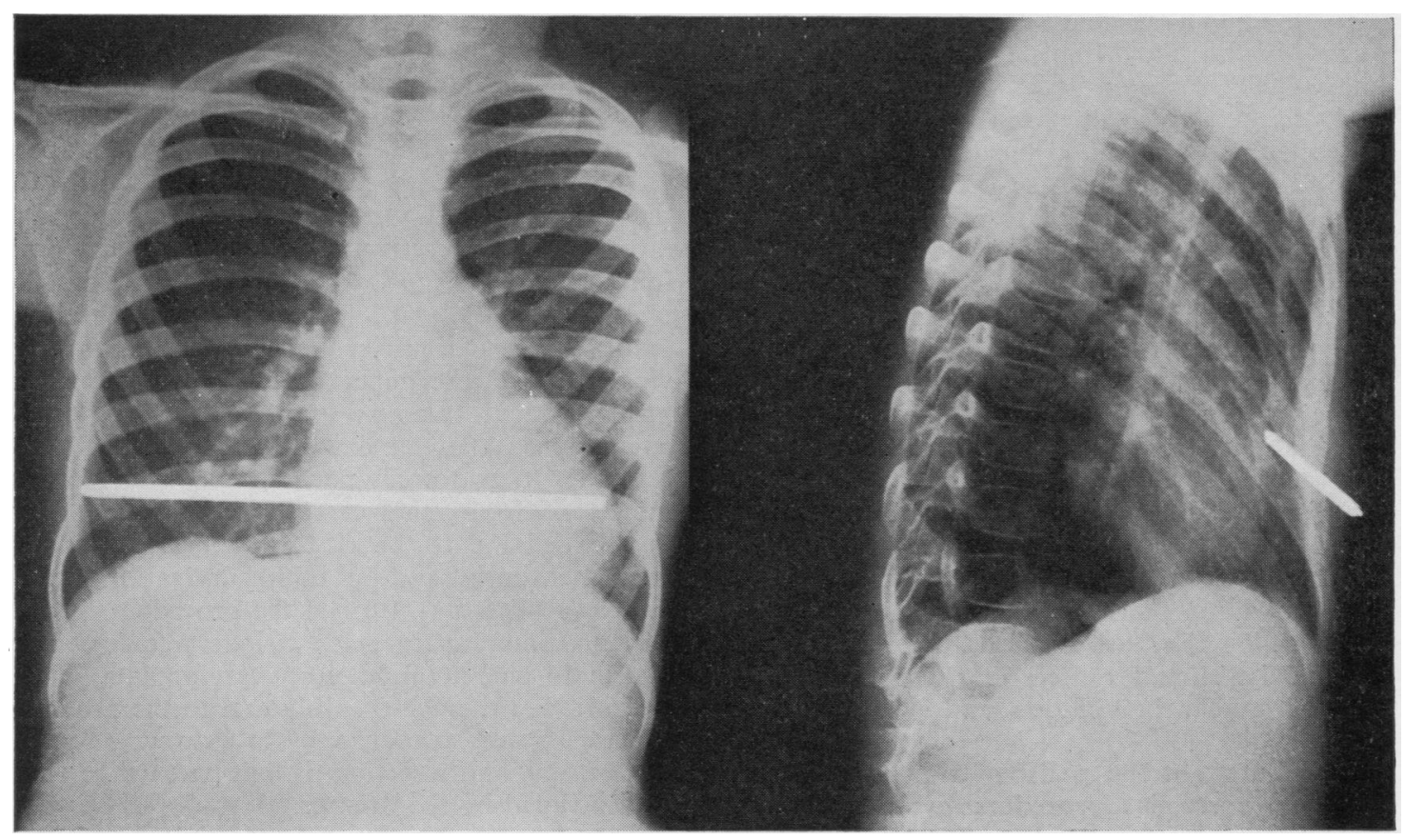

FIG. $2 b$

FIG. 2a. (Left) Shows a typical funnel chest deformity; (right) the same patient after correction of the deformity. FIG. $2 b$. P.A. and lateral films showing a Steinmann's pin deep to the mobilized sternum and superficial to the lateral ribs, used to maintain stability of the sternum after correction of the defect in the patient whose pre-and post-operative lateral films are shown in Fig. $2 a$. 
sternal and costal fractures is known, and the patient has not been jeopardized by gross trauma and a period of uncontrolled paradoxical respiration.

Homologous rib struts passed horizontally behind the sternum have been used, the ends of the rib resting laterally on the bony chest wall at the margins of the defect (Dorner et al., 1950). Ribs have the advantage of easy availability, and two disadvantages: (1) the length of rib used inevitably curves and lies conveniently only with its concavity dirested anteriorly, so that the deformity tends to be under-corrected and the lateral ends of the rib project forward; (2) the thoracoplastic effect of resection of a single rib is appreciable, and, while of value in thoracotomy for limited pulmonary resection (le Roux, 1961), is undesirable in a patient whose respiratory reserve is already diminished by chest deformity.

Steinmann's pins have been used to maintain stability of the sternum. Holmes (1957) skewered the sternum in its length, across the osteotomy, to fix the gladeolus to the manubrium at an appropriate angle, the pin emerging through the skin of the anterior abdominal wall, and traction being maintained on the projecting end. In his cases the pin was removed after two or three weeks. Griffin and Minnis (1957) and Mayo and Long (1962) reported series in which the mobilized sternum was transfixed from side to side between the anterior and posterior cortical tables at the level of the fourth or fifth cartilage. Either a Steinmann's pin or a Kirschner wire was used, and the support became cutaneous just below the nipples where the points were protected with corks and a collodion dressing was used to cover the sites of pin-puncture ; the pin was removed after three weeks. A Kirschner wire is a dangerously slender sternal support.

Paltia et al. (1959) advocated the use of stainless steel struts to support the sternum, and variations on this technique have been described by Adkins and Blades (1961) and by Jensen, Schmidt, and Garamella (1962). The last-mentioned authors designed a set of malleable stainless steel alloy struts which they have called 'stribs' and which they advise should be left in situ for the better part of a year in children and permanently in adults.

In Edinburgh, the patients with funnel chests in whom corrective prosedures were undertaken in the early part of the last decade were nearly all children; in these patients the sternum was not supported, correction was satisfactory in all except one, in whom a second operation became necessary, and in most of them paradoxical move- ment of the mobilized sternum proved are embarrassment in the early post-operative period흠. During this period 11 patients were treated. Five patients were subsequently managed by mobiliza tion of the sternum and its support with an homos logous rib strut; in these, the disadvantages of this procedure enumerated above were recognized:A Steinmann's pin has been used in six successiv $\overrightarrow{\omega^{2}}$ patients in the simplest possible way, by laying the pin across the gap created by the excision of deformed cartilage deep to the sternum and super- ficial to the ribs laterally. The ends of the ping have been left buried under the skin where one of other is easily found by palpation six to eight weeks later, and the pin is withdrawn through of small incision. The sternum has been secure from the moment of recovery from anaesthesia in alf

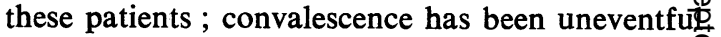
and the chest wall solid after removal of the pin 3 The pre- and post-operative films of one of these्ष patients are shown (Fig. $2 \mathrm{a}$ and b).

\section{TUMOURS OF THE CHEST WALL}

Primary rib tumours are not common; metastatio rib tumours are often multiple and do not there fore present a surgical problem ; bronchial carcio noma which invades the chest wall is relativel infrequently amenable to resection. In Edin burgh, during a 10-year period when $3,00 \Phi$ patients with bronchial carcinoma were seen, part of the chest wall was resected in 40 patients. Of these resections, 18 were undertaken for rib lesions thought pre-operatively to be primary rie tumours; of the 18, four were shown to be plasmacytomata, and in these patients generalized manifestations of their disease later became ob 3 vious; two were metastases from unsuspected primary renal tumours in patients with norma pyelograms; the remaining 12 were primary rib tumours. In two other patients resection of a riß metastasis from renal carcinoma was undertake in the belief that the rib lesion represented the only metastasis, and in both survival for morer than two years has justified the procedure. In five patients, inflammatory rib lesions were resected, and in 15 patients pulmonary carcinomata, which్ had invaded the chest wall lateral to the posterior rib angle, were managed by lobectomy or pneue monectomy and resection of that part of the chese wall invaded by the tumour.

There is no clearly defined circumstance it which it is necessary to repair with autogenou or prosthetic material a defect in the chest wat as opposed simply to covering the defect with the overlying soft tissues or the scapula. Wide exck 
sion of rib tumours is a prerequisite of adequate surgical management, and it is usually necessary to resect at least $6-7$ in. $(15-18 \mathrm{~cm}$.) of three ribs and the soft tissues of the two intercostal spaces between the ribs. When the defect left after the resection of such an area of chest wall is covered by scapula, it is probably not necessary to support the chest other than by formal closure of the thoracotomy. A defect of similar size elsewhere, and especially anteriorly, should be repaired both to prevent paradoxical movement with respiration and for cosmetic reasons.

A wide range of autogenous material has been used to support the chest wall after the ablation of tumours-periosteal flaps, musculoperiostealosseous flaps, free rib grafts, tibial grafts, fascia lata, rectus sheath, breast flaps, sliding flaps of latissimus dorsi and pectoralis major, and full thickness skin grafts. None except bone is sufficiently rigid, and it is now rare to read of the use of autogenous material in the repair of defects in the thoracic wall. In recent years prosthetic materials have been used with increasing frequency, and it is possible to suggest the prerequisites of the ideal prosthetic material for this purpose. The material should be and remain suffi- ciently rigid to abolish paradox. It should be inert, tolerated, and incorporated by the host, able to be manipulated and shaped to fit a defect the extent of which cannot be determined before operation, and it should be radio-translucent so as not to obscure the lung fields on post-operative chest radiographs.

Metals - tantalum and stainless steel as plates or mesh-are unsatisfactory (Effler, 1953 ; Indyk and Rundle, 1957). They are radio-opaque; the plates are almost unmanageable and difficult to secure ; the meshes fragment so that they do not certainly prevent paradox, and the fragments may be extruded (Fig. 3). Plastic materials-teflon mesh, fibreglass cloth, lucite plates, ivalon, marlex mesh, and acrylic resin-are all radio-translucent. The term 'plastic' is commercial jargon to which no strictly scientific definition can be applied. A plastic is an artificial material, usually polymeric in structure and of organic origin, which at some time during its manufacture has been shaped by flow, and which is not rubber, metal, ceramic, wood or leather. The plastic meshes and cloths can be cut precisely to fit a defect in the chest wall and are incorporated by the host, but they lack rigidity. Ivalon and fibreglass tend to be

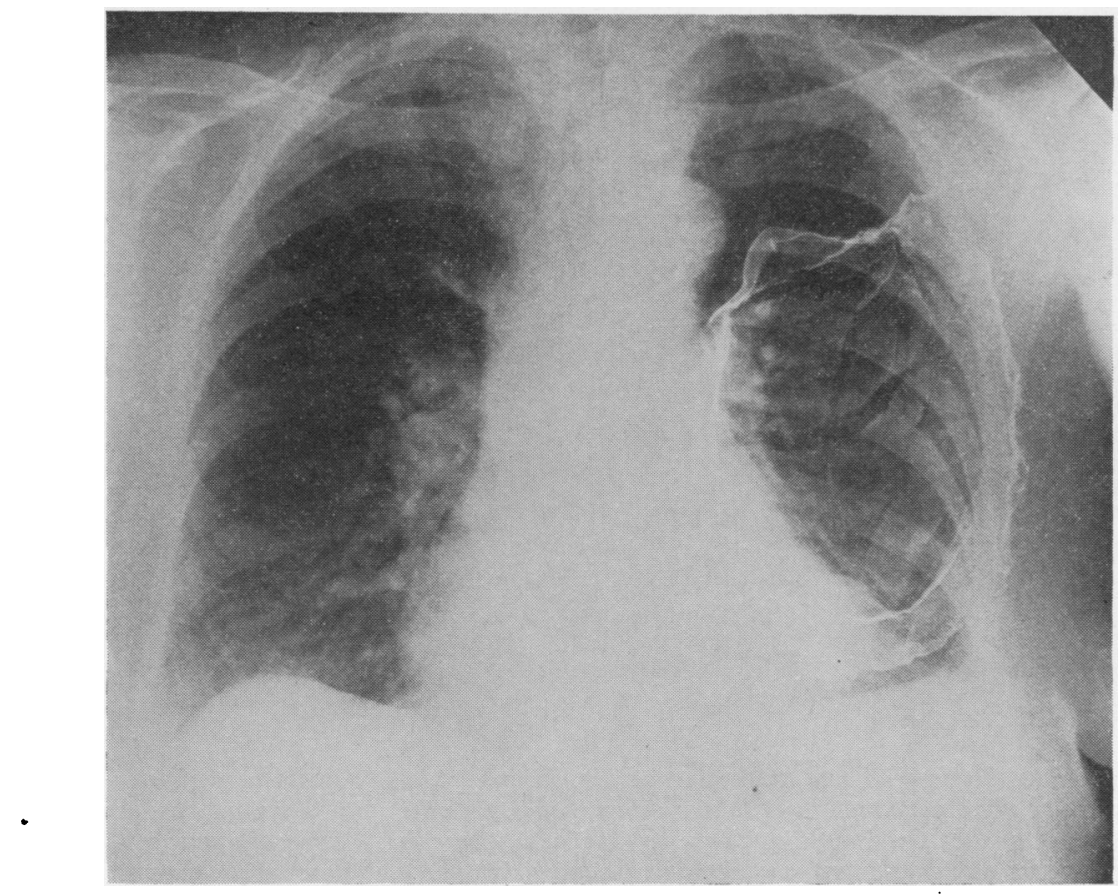

FIG. 3. Fragmented tantalum mesh used inappropriately to control inadequately paradoxical movement of the chest wall after excision of a rib tumour. 


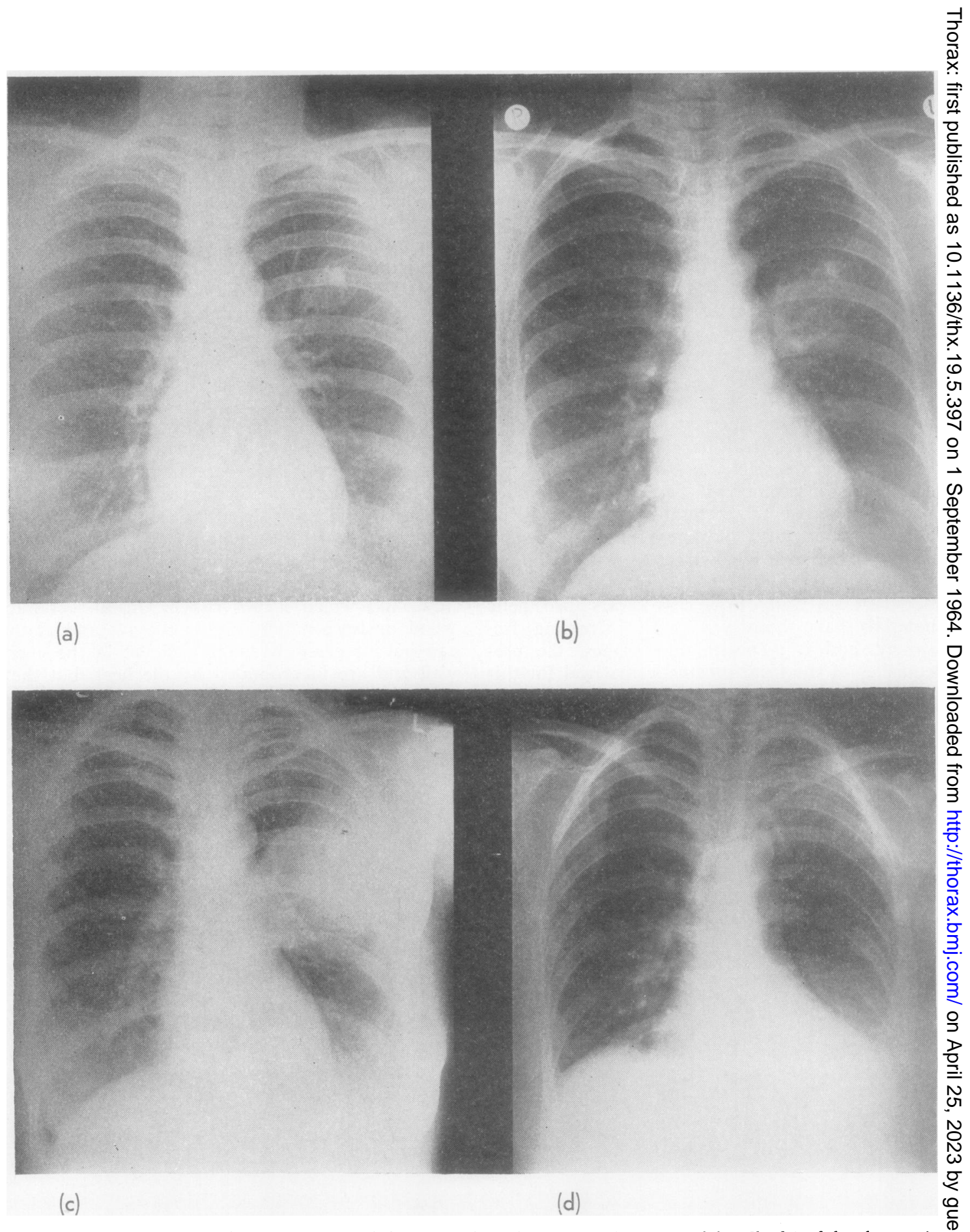

FIG. 4. The rib tumour at the anterior end of the second left rib was initially managed by ill-advised local resection which, from the operative note, amounted to little more than biopsy. The histological report was 'chondroma'. (a) Film' made before biopsy; ( $b$ and $c)$ Growth of tumour over the next two years. The patient was then rejerred to the Regional Thoracic Unit in Edinburgh and photographs made during the operation of tumour resection are shown in $\mathbb{\Phi}^{+}$ Fig. 5. The post-operative film $(d)$ demonstrates that acrylic resin used to maintain chest wall stability after resection $\frac{1}{1}$ of the second, third, and fourth ribs anteriorly does not obtrude on the chesi radiograph. The tumour was then called a chondrosarcoma. 


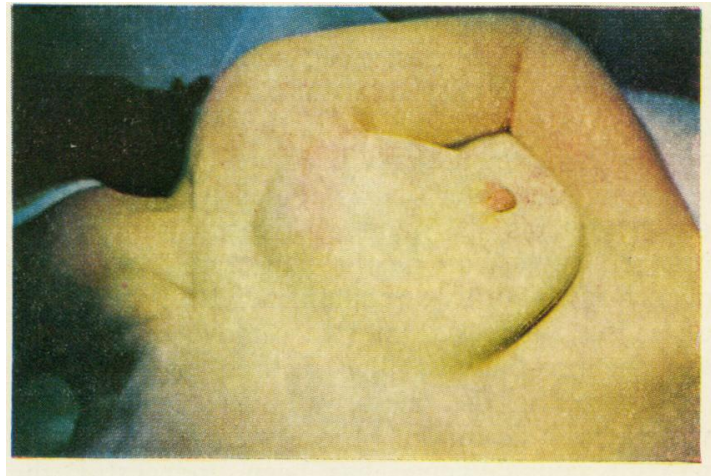

(a)

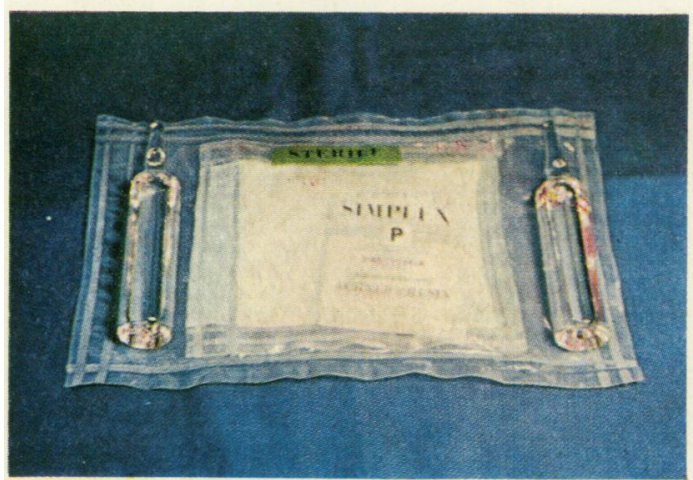

(c)

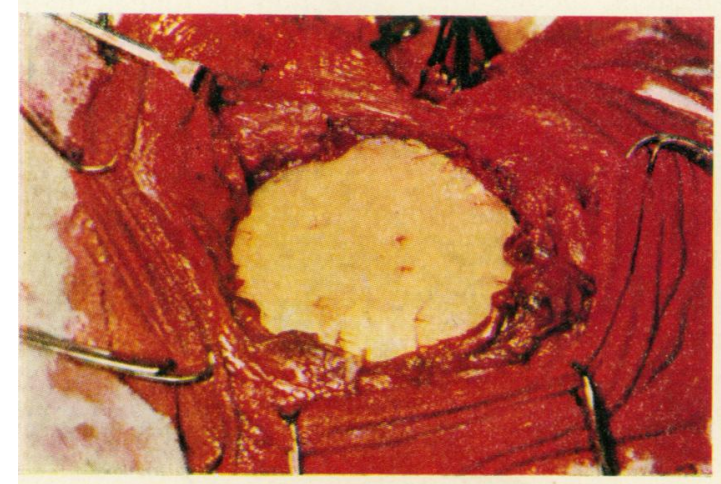

(e)

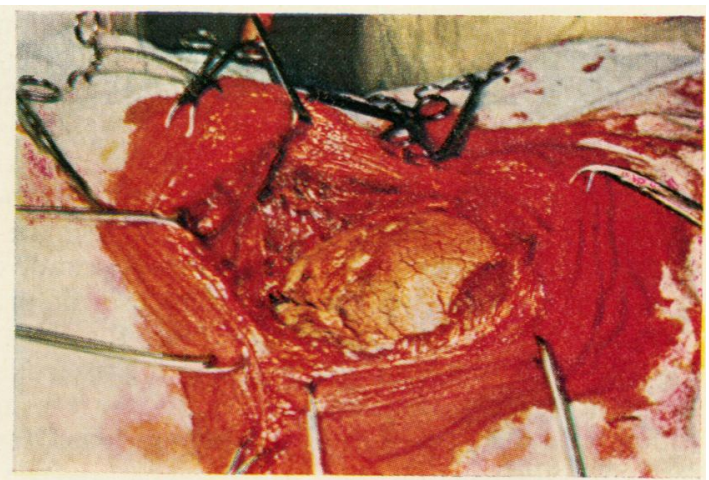

(b)

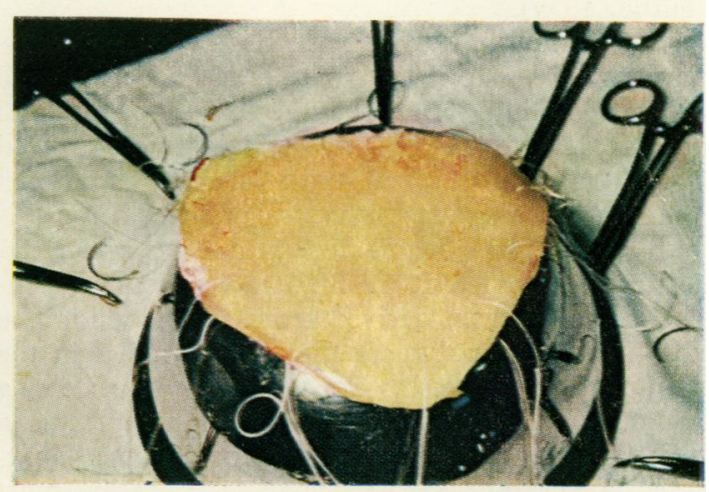

(d)

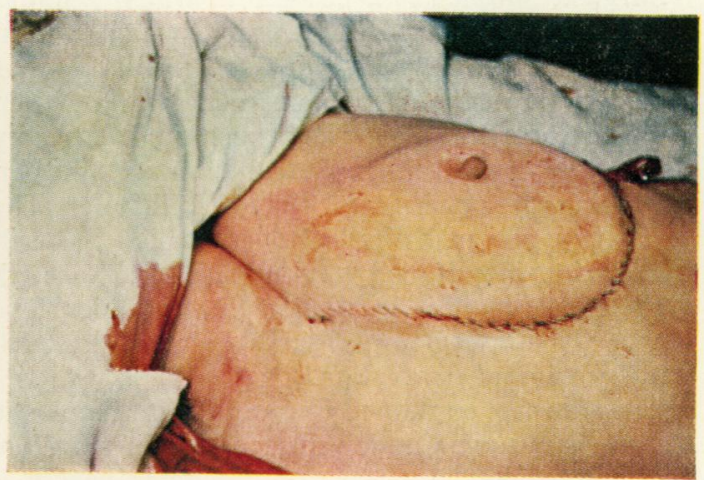

(f)

FIG. 5. The patient whose chest radiographs are shown in Fig. 4 was submitted to resection of the rib tumour. (a) The scar of the previous biopsy can be seen over the chest wall swelling, produced by the tumour, between the left clavicle and the nipple. (b) The defect left in the chest wall after excision of three ribs. (c) The packet of powder and two ampoules of liquid, one of which when mixed with the powder will produce the prosthesis. (d) The prosthesis has been made and sutures have been inserted around its periphery. The prosthesis lies over an upturned basin to reproduce the convexity of the anterior chest wall while the acrylic hardens. (e) The prosthesis is in situ. (f) At the end of the operation. 
rejected, especially in the presence of infection (Usher and Wallace, 1958). Lucite is not conveniently manipulated at operation. Marlex mesh (Graham, Usher, Perry, and Barkley, 1960) is regarded with enthusiasm in the American literature, and it fulfils many of the criteria of a satisfactory chest wall prosthesis. It does not immediately control all paradox, but control of paradox is said to be adequate, and the mesh form of the material allows of incorporation in the host. Marlex is a polyethylene with a high tensile strength easily made into a monofilament from which mesh can be made. It is said to excite less foreign body reaction than, for example, dacron, orlon, or nylon, and it is not rejected in the presence of infection (Usher, Fries, Ochsner, and Tuttle, 1959).

In Edinburgh, acrylic resin has been used satisfactorily to restore the rigidity of the chest wall after resection of rib tumours. The material (Surgical Simplex $\mathbf{P}^{1}$ ) was originally borrowed from the neurosurgical unit where it had been used for cranioplasty. The use of acrylic for this purpose is well documented (Robinson and Macalister, 1954 ; Rietz, 1958). An acrylic is a synthetic plastic resin derived from acrylic acid. The two important polymers that are included in the group of acrylic resins are polymethyl acrylate, a tough rubbery material used, for example, as a safety-glass interlay, and polymethyl methacrylate, a hard clear thermoplastic resin most familiar as 'perspex' and used extensively in dentistry.

Surgical Simplex is a powder to which a liquid is added to form a putty-like paste which, within a few minutes, changes, with the production of considerable heat, to an inert solid state. When in paste form the plastic can be moulded to any shape, cut, and transfixed with sutures, and on hardening it retains its shape faithfully. The liquid is a powerful lipoid solvent which is sterilized during manufacture by being passed through a bacterial filter; it is supplied in ampoules. The powder is supplied in plastic packets and is sterilized by gamma irradiation.

The powder, contained in an inner sterile plastic packet, is removed under surgical conditions from an outer packet, a corner of the inner packet is snipped off, and the liquid contents of an ampoule are poured into the packet. Within a few minutes of mixing, a paste is formed of a sufficiently tacky consistency to allow a thin $\left(\frac{1}{4}-\frac{1}{8}\right.$ in.) sheet of the material to be moulded by hand within the plastic packet. This sheet can be cut, together with its

\footnotetext{
${ }^{1}$ Obtainable from North Hill Plastics, Limited, London
}

containing packet, to the shape required to fille the defect in the chest wall, and a series of silk을. sutures can be placed around the periphery of the prosthesis. After some six to eight minutes the prosthesis quite suddenly becomes hot, and when a few minutes later, it has cooled it is very hard, $\vec{P}$ and it retains its shape. It is still sandwichedbetween layers of plastic, the remains of the $\vec{\omega}$ packet in which it was contained. These are peeledo off in such a way as not to remove the sutures, $\overrightarrow{\vec{x}}$ and the prosthesis is then secured in position.

A defect in the chest wall has been repaired with acrylic resin on 14 occasions. In these $14 \omega_{0}$ patients convalescence has been uneventful, the chest wall has been completely rigid at the siteo of the defect, and paradoxical respiration has not occurred. The first few patients, in whom the acrylic prosthesis has now been in situ for sixO years, remain well. The pre- and post-operative 3 chest radiographs and intra-operative photograph㝏 of a patient with a chondrosarcoma of the chest wall, in whom the tumour was resected and thes defect closed with acrylic resin, are shown in + Figs. 4 and 5.

\section{SUMMARY}

The maintenance of chest wall stability after accidental and surgical disruption of part of the chest wall is discussed, and the techniques used in Edin-o burgh for the management of the unstable chest wall are outlined. Flail chest is managed with intermittent positive pressure respiration; the sternum, mobile after correction of funnel chest deformity, is supported with a Steinmann's pin a defect left after resection of part of the ches: wall is closed with acrylic resin.

\section{REFERENCES}

Adkins, P. C. and Blades, B. (1961). A stainless steel strut for correce tion of pectus excavatum. Surg. Gynec. Obstet., 113, 111.

Avery, E. E., Mörch, E. T., and Benson, D. W. (1956). Critically crushed chests. J. thorac. Surg., 32, 291.

Barrett, N. R. (1960). The treatment of stove-in chest. Lancet, 졷

Blades, B. and Kent, E. M. (1940). Individual ligation technique fo lower lobe lobectomy. J. thorac. Surg., 10, 84.

Brown, A. L. (1939). Pectus excavatum (Funnel chest). Ibid., 9, 164.

Carter, B. N., and Giuseffi, J. (1951). Tracheotcmy : A usefu円 procedure in thoracic surgery, with particular reference to itfs employment in crushing injuries of the thorax. Ibid., 21, 495. $\mathrm{W}$

Chin, E. F. and Adler, R. H. (1954). The surgical treatment of pectug excavatum (funnel chest). Brit. med. J., 1, 1064. logical . P. and Coleman, C. L. (1950). Fracture of ribs- $\$$ Crutegical treatment. Surg. Gynec. Obstet.,90, 129.

instab. R. and Nolen, T. M. (1956): Multiple rib fracture wit

instability of chest wall. J. thorac. Surg., 32, 15.

Ibid., 35, 719.
Ibiel, R. The surgical treatment of pectus excavatum Ibid., 35, 719. excavatum. Ibid., 20, 444.

Effler, D. B. (1953). Prevention of chest wall defects : Use of tantalun and steel mesh. Ibid., 26,419

Graham, J., Usher, F. C., Perry, J. L., and Barkley, H. T. (1960) Marlex mesh as a prosthesis in the repair of thoracic wall defects Ann. Surg., 151, 469. 
Griffin, E. H., and Minnis, J. F. (1957). Pectus excavatum : A survey and a suggestion for maintenance of correction. J. thorac. Surg., 33,625 .

Griffiths, H. W. C. (1960). Crush injuries of the chest. J. roy. Coll. Surg. Edinb., 6, 12.

Heroy, W. W., and Eggleston, F. C. (1951). A method of skeletal traction applied through the sternum in 'steering wheel' injuries of the chest. Ann. Surg., 133, 135.

Holmes, C. L. (1957). Pectus excavatum. Surgical technique: A new form of external traction to the elevated sternum. J. thorac. Surg., 33, 321 .

Hudson, T. R., McElvenny, R. T. and Head, J. R. (1954). Chest wall stabilization by soft tissue traction. J. Amer. med. Ass., 156, 768.

Indyk, J. S. and Rundle, F. F. (1957). Closure of a chest wall defect with tantalum mesh gauze. Med. J. Aust., 2, 465.

Jensen, N. K., Schmidt, W. R., and Garamella, T. J. (1962). Funnel chest : A new corrective procedure. J. thorac. Surg., 43, 731 .

le Roux, B. T. (1961). Techniques of Thoracotomy. E. \& S. Livingstone, Edinburgh and London.

Lester, C. W. (1950). Funnel chest : Its cause, effects and treatment. J. Pediat., 37, 224.

Mayo, P. and Long, G. A. (1962). Surgical repair of pectus excavatum by pin immobilisation. J. thorac. Surg., 44, 53 .
Paltia, V., Parkkalainen, K. V., Salamaa, M., and Wallgren, G. R. (1959). Operative technique in funnel chest. Acta chir. scand., 116, 90.

Proctor, H. and London, P. S., (1955). The stove-in chest with paradoxical respiration. Brit. J. Surg., 42, 622.

Ravitch, M. M. (1958). Operation for correction of pectus excavatum. Surg. Gynec. Obstet., 106, 619.

(1961). Operative treatment of congenital deformities of the chest. Amer. J. Surg., 101, 588.

Rietz, K.-A. (1958). The one-stage method of cranioplasty with acrylic plastic. J. Neurosurg., 15, 176.

Robinson, R. G., and Macalister, A. D. (1954). Acrylic cranioplasty. A simple one-stage method using a cold curing material. Brit. $J$. Surg., 42, 312

Sandor, F. F. (1963). Treatment of stove-in chest with "paradoxical respiration" in peripheral hospitals. Thorax, 18, 116 .

Sillar, W. (1962). The crushed chest. J. roy. Coll. Surg. Edinb., 7, 101.

Usher, F. C. and Wallace, S. A. (1958). Tissue reaction to plastics. Arch. Surg., 76, 997.

- Fries, J. G., Ochsner, J. L., and Tuttle, L. L. D. (1959). Marlex mesh, a new plastic mesh for replacing tissue defects. Ibid., 78, 138

Windsor, H. M. and Dwyer, B. (1961). The crushed chest. Thorax, 16, 3. 